\title{
Mechanical strength of silica fiber splices after exposure to extreme temperatures
}

\author{
Marcus Perry*a ${ }^{\mathrm{a}}$, Pawel Niewczas ${ }^{\mathrm{a}}$, Michael Johnston ${ }^{\mathrm{b}},{\text { Kevin } \text { Cook }^{\mathrm{c}} \text { and John Canning }}^{\mathrm{c}}$ \\ ${ }^{a}$ Institute for Energy and Environment, University of Strathclyde, Glasgow G1 1XW, UK \\ ${ }^{\mathrm{b}}$ EDF Energy Nuclear Generation Ltd, GSO Business Park, East Kilbride, G74 5PG, UK \\ 'Interdisciplinary Photonics Laboratories, School of Chemistry, University of Sydney, Australia
}

\begin{abstract}
By using a combination of type-I and regenerated gratings, the mechanical strength of optical fiber splices after exposure to temperatures over $1300{ }^{\circ} \mathrm{C}$ was characterized. Splice strength was found to decrease with temperature with a secondorder polynomial dependence after exposure to environments hotter than $500{ }^{\circ} \mathrm{C}$. Splices exposed to temperatures above $1300{ }^{\circ} \mathrm{C}$ were $80 \%$ more fragile than non-exposed splices. The lack of optical attenuation and the narrowing distribution of breaking strengths for higher temperatures suggest surface damage mechanisms, such as hydrolysis, play a key role in weakening post-heating and that damage mechanisms dominate over strengthening induced by crack melting.
\end{abstract}

Keywords: optical fiber mechanical strength, splice, heat exposure, regenerated grating.

\section{INTRODUCTION}

Ensuring the mechanical integrity of optical fiber splices exposed to high temperatures after deployment and during the fabrication of brazed sensor packages ${ }^{1}$ is crucial in ensuring long-term reliability. This applies to both measurement and communication systems operating in harsh environments. The strength of splices after exposure to extreme temperatures is particularly important for strucutral ${ }^{2}$ and geodynamical ${ }^{3}$ monitoring systems, but large fluctuations in environmental strain and temperature are also common within applications in aerospace, nuclear and oil and gas industries ${ }^{4,5}$.

In this work, the strength of fiber splices exposed to temperatures up to $1300{ }^{\circ} \mathrm{C}$ is investigated. A combination of type-I and regenerated gratings ${ }^{6}$ allow the thermal and mechanical loads on each splice to be fully characterized over a large temperature and strain range. This is, to our knowledge, the first time the strength of fiber splices has been tested after high temperature exposure.

\section{THEORETICAL BREAKING STRENGTH}

While the strength of pristine silica fibers can be as high as $14 \mathrm{GPa}^{7}$, surface flaws introduced during sensor fabrication reduce the stress required to realize fracture. The Griffith's criterion describes how stress at fracture, $\sigma_{f}$, is related to the depth of the deepest flaw, $a$, in the fiber ${ }^{8}$ :

$$
\sigma_{f} \propto a^{-1 / 2}
$$

When untampered with, the flaw sizes in a fiber follow a Wiebull distribution. However, further damage is introduced during processes such as coat stripping, the writing of Fiber Bragg Gratings (FBGs) and splicing?. Whereas FBG fabrication causes minimal decreases in strength ${ }^{10}$, the flaws introduced by splicing can lead to a strength degradation of up to $80 \%$ of the original value, depending on the splicing method used ${ }^{11}$.

With electro-arc fusion splicing, used herein, silica fusion causes weaknesses in the vicinity of the splice, with fiber fracture generally occurring in the heat-affected zone ${ }^{12}$. Post-splice heat treatments such as a $700{ }^{\circ} \mathrm{C}$ fire-polish may be used to clean the fiber surface and melt surface cracks ${ }^{13}$, but the effects of prolonged heating post-splicing has, as yet, remained untested. In this work, FBG sensors are used to monitor temperature and strain during splice heating and stressing. Axial strain, $\varepsilon_{z}$, and temperature shifts, $\Delta T$, induce linear fractional shifts in the FBG's Bragg wavelength via $\Delta \lambda_{B} / \lambda_{B}=\left(1-p_{e}\right) \varepsilon_{z}+C_{T} \Delta T$, where $p_{e}=0.22$, and $C_{T}$ are the strain-optic and temperature coefficients of silica respectively.

*marcus.perry@strath.ac.uk; phone +44 (0)141 548 4841; fax +44 (0)141 548 4872; www.instee.strath.ac.uk 


\section{EXPERIMENTAL}

As brief acid stripping has been found to have little effect on the integrity of fibers ${ }^{14,15}$, plated fiber specimens are soaked in $63 \%$ nitric-acid for 1 minute to remove their metallic coat. The polymer coats of SMF-28 fibers are mechanically stripped. Fibers are then cleaned with ethanol, cleaved and inserted into a BFS-60CCD fusion splicer. A prefusion cleaning routine of $20 \mathrm{~mA}$ current for $0.1 \mathrm{~s}$ removes carbon underlayers and contaminants. A hot-push under $15 \mathrm{~mA}$ current for $3 \mathrm{~s}$ allows fusion. Mechanical abrasion and exposure to humidity lead to surface roughening via hydrolysis ${ }^{16}$, so splice heating and breaking strength tests are performed immediately after splicing.

Fibers are affixed to a translation stage by magnets as shown in Figure 1a). The spliced region is enveloped by a steel heat susceptor, Figure 1b), which is in turn heated by a $40 \mathrm{~mm}$ diameter induction coil, operating at a current of $200 \mathrm{~A}$ and frequency of $370 \mathrm{kHz}$. Heating time is varied from 0 to $35 \mathrm{~s}$, before splices are allowed to cool for 3 minutes. The fiber is then removed from the heating rig, while points A and B labeled in Figure 1 are clamped using screws and moved apart by a translation stage. Meanwhile, interrogation of a type I FBG is used to infer the breaking strain.

a)

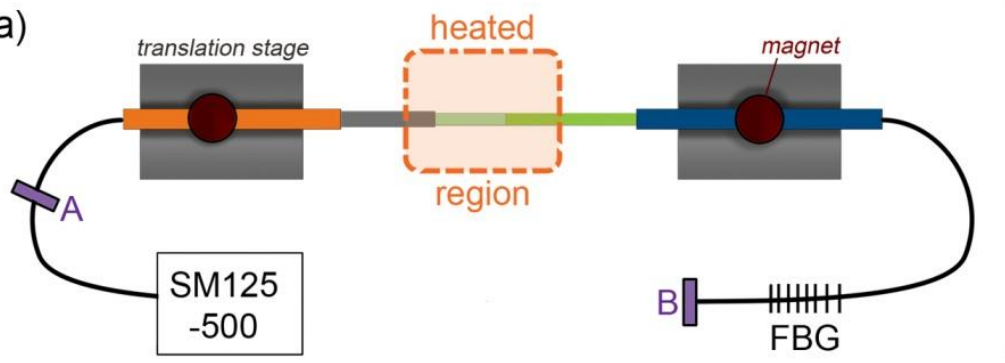

b)

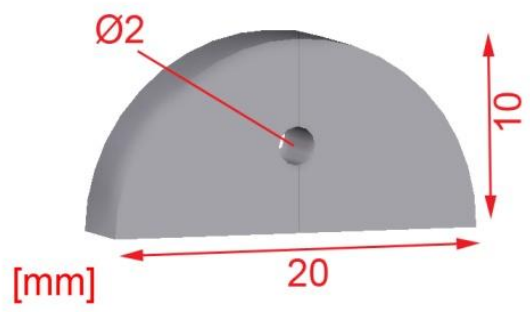

Figure 1. a) Susceptor-induction coil set up used to heat splices. Points A and B are later clamped and moved apart by a translation stage, while the sm125-500 interrogation unit measures strain in the labeled FBG. b) Dimensions of heat susceptor used to expose splices to elevated temperature.

The relationship between induction time and temperature is found by replacing the splice in Figure 1 with a regenerated grating, fabricated similar to previous work ${ }^{17}$. A tunable laser unit (Micron Optics sm125-500) is used to measure Bragg shifts with $5 \mathrm{pm}$ wavelength resolution at a rate of $2 \mathrm{~Hz}$. Measured heat profiles and maximum temperatures for varying times are shown in Figure 2. Heating the gratings in an oven up to $300{ }^{\circ} \mathrm{C}$ in $50{ }^{\circ} \mathrm{C}$ steps allows characterization of $\mathrm{C}_{\mathrm{T}}$ and extrapolation to $1300{ }^{\circ} \mathrm{C}$. It has been previously confirmed that $C_{T}$ for regenerated gratings is linear up to $1000{ }^{\circ} \mathrm{C}^{17}$.

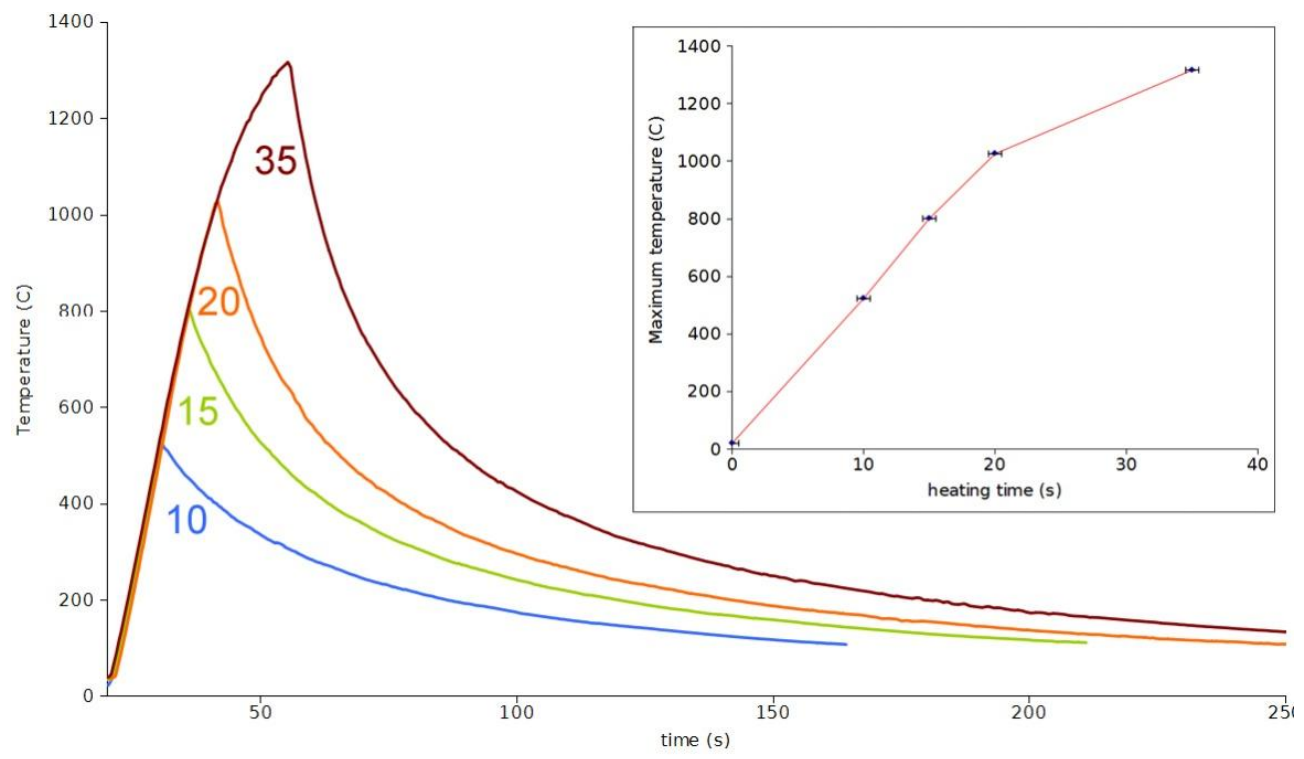

Figure 2. Heating profiles for 10, 15, 20 and $35 \mathrm{~s}$ induction heating times at $200 \mathrm{~A}$ and $370 \mathrm{kHz}$. Shown inset is the heating time vs maximum temperature relationship, which is linear until saturation due to increased radiative cooling. 


\section{RESULTS AND DISCUSSION}

Fibers were strained at $0.4 \mathrm{~m} \varepsilon / \mathrm{s}$ to failure 40 times for each temperature point to ensure statistical significance. Repeated breaking at the splice implied this was always the largest flaw. A selection of breaking strength distributions are shown in Figure 3, along with a typical strain profile. These show a clear decrease in strength with increasing heat exposure.

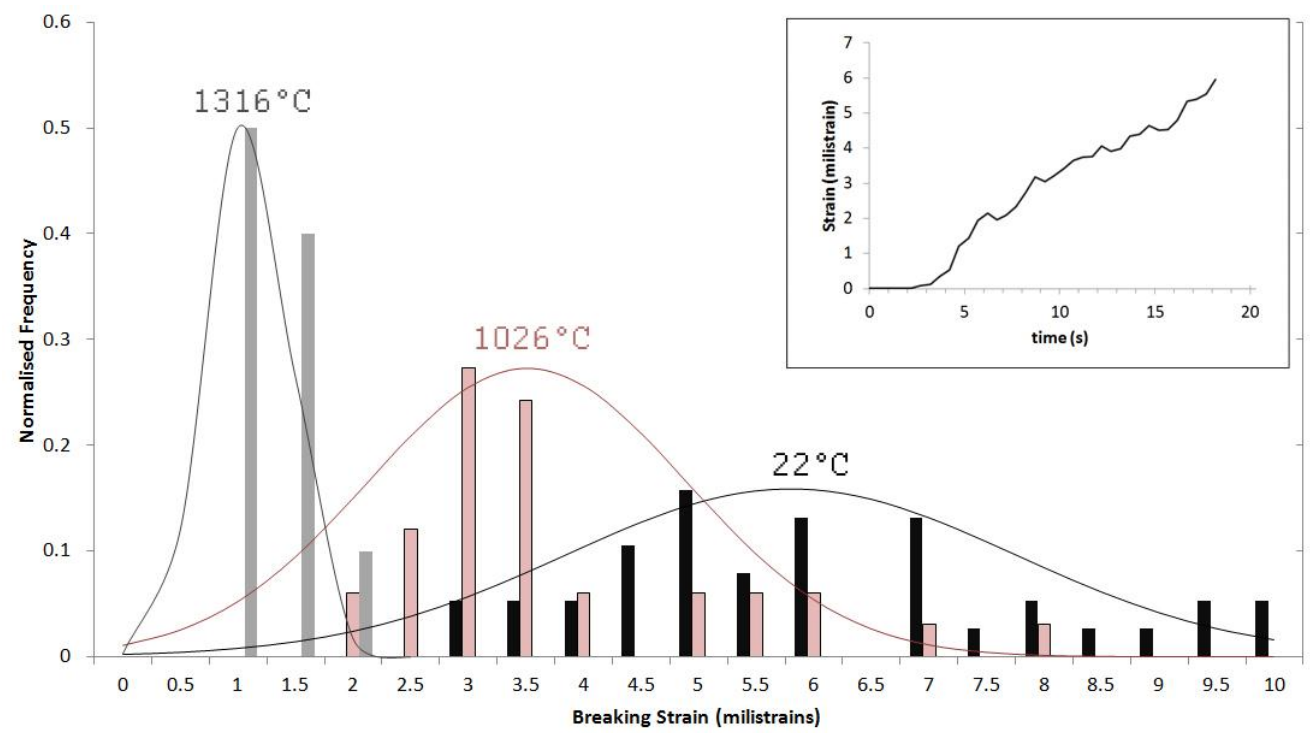

Figure 3. Normalised distribution of breaking strains of fiber splices heated to 1316,1026 and $22{ }^{\circ} \mathrm{C}$. A typical strain profile measured by the FBG during a splice stress test is shown inset

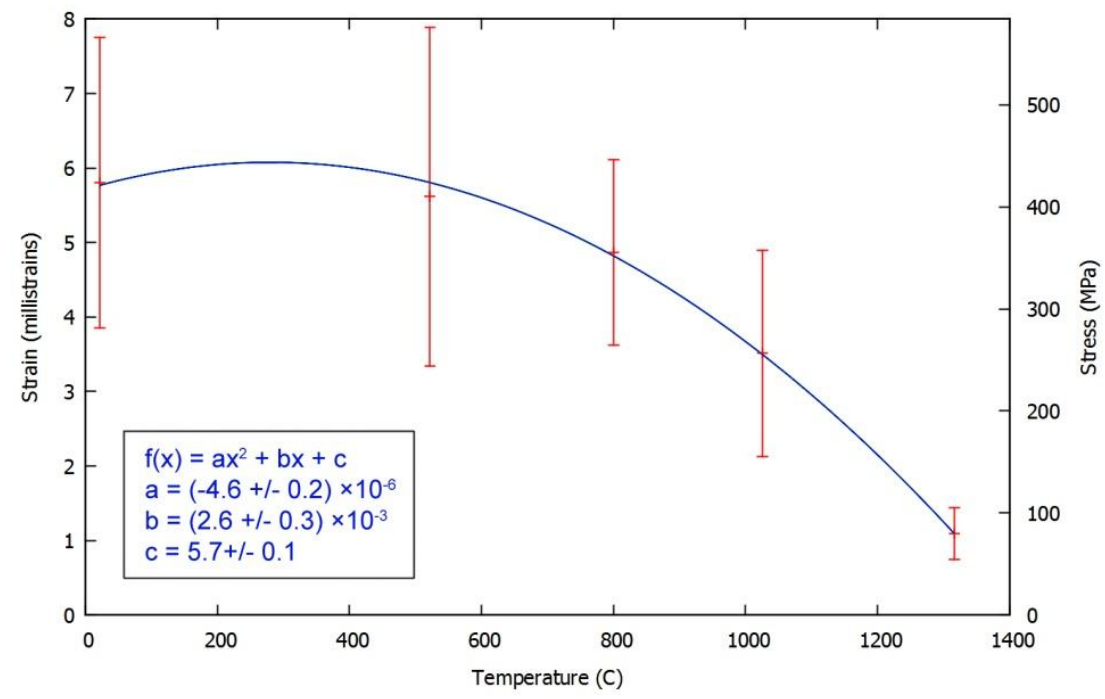

Figure 4. Summary of splice strength after exposure to elevated temperature, with second-order polynomial fit.

Average splice breaking strength as a function of temperature is shown in Figure 4 . Heating to $500{ }^{\circ} \mathrm{C}$ causes almost no decrease in splice strength, agreeing with previous experiments performed with non-spliced fibers ${ }^{18}$. Exposure to higher temperatures reduced splice strength with a second-order polynomial dependence. Splices heated to $1316{ }^{\circ} \mathrm{C}$ displayed approximately an $80 \%$ decrease in strength. Throughout the experiments, heating led to very little optical attenuation, implying that damage was restricted to the fiber surface. As the rate of hydrolysis of silica is temperature dependent, it is likely that heating leads to accelerated ageing of spliced fiber surfaces ${ }^{14}$. While temperatures $>700{ }^{\circ} \mathrm{C}$ may have caused crack melting, the reduction in strength shows damage mechanisms at the heat-affected zone dominate; a hypothesis further supported by the reduced distribution of strengths at higher temperatures. Even in the unheated case, splicing has 
reduced the strength of fibers to $10 \%$ of given manufacturer values. This is consistent with published data, but implies weakening via contaminants from the splicer and also the mechanical method of polymer coat stripping ${ }^{19}$. Nevertheless, the randomized, unbiased errors demonstrate that repetition of the experiment was consistent. This provides confidence that the reduction in strength with temperature is independent of other factors such as mechanical abrasion ${ }^{20}$.

\section{CONCLUSIONS}

It has been demonstrated that the strength of fiber splices decreases with a second-order polynomial dependence after exposure to temperatures above $500{ }^{\circ} \mathrm{C}$ in ambient environments. The lack of optical attenuation after heating implies that surface damage due to hydrolysis of the glass network in the vicinity of the splice was the cause of embrittlement. Heat damage was further supported by a reduction in the deviation of breaking distributions after exposure to increased temperature. This work demonstrates the importance of reducing splice stress after exposure to high temperatures. This highlights a major issue with the combined stress and heat exposure of conventional soldering methods. As such, the recommendation is to avoid using brazing methods to embed fiber splices directly into metal structures.

\section{REFERENCES}

[1] P. Niewczas and G. Fusiek, "Induction heating assisted optical fiber bonding and sealing technique," 21st International Conference on Optical Fiber Sensors, SPIE 7753, 77536H, 2011.

[2] J. Ou, Z. Zhou, and X. Zhao, "Encapsulation Techniques for FBGs and Smart Monitoring for Bridges with FBG Sensors", pp. 180-187. Stanford: DEStech Publications Inc, 2003.

[3] P Ferraro, G Natale, "On the possible use of optical fiber Bragg gratings as strain sensors for geodynamical monitoring”, Optics and Lasers in Engineering 2-3, vol 37, pp115-130, 2002.

[4] A. D. Kersey, "Optical Fiber Sensors for Permanent Downwell Monitoring Applications in the Oil and Gas Industry," no. 3, pp. 400-404, 2000

[5] E Udd, W Schulz, J Seim, M Morerell, T Weaver, J Bush, G Adamovsky, "Fiber Optic Distributed Sensing Systems For Harsh Aerospace Environments", Smart Structures and Materials proc vol 3674, 1999.

[6] J. Canning, S. Bandyopadhyay, M. Stevenson, P. Biswas, J. Fenton, and M. Aslund, "Regenerated gratings," J. European Opt. Soc. - Rapid Publications, vol. 4, 2009.

[7] C. Kurkjian, P Gupta, R Brow, "The Strength of Silicate Glasses: What Do We Know, What Do We Need To Know?”, Int J Appl Glass Science, vol 1, pp. 27-37, 2010.

[8] A. A. Griffith, "The Phenomena of Rupture and Flow in Solids,' Philos. Trans. Royal Soc. London, A221, pp 163198, 1920.

[9] R. Olshansky, “Tensile strength and fatigue of optical fibers,” J App Phy, vol. 47, 1976, p. 4497

[10] H. Yoon and C. Kim, "The mechanical strength of fiber Bragg gratings under controlled UV laser conditions," Smart Materials and Structures, vol. 16, 2007, pp. 1315-1319.

[11] C. Kurkjian, J. Krause, and M. Matthewson, "Strength and fatigue of silica optical fibers," Journal of Lightwave Technology, vol. 7, pp. 1360-1370, 1989.

[12] J. Senior, M. Jamro, “Optical Fiber Communications: Principles and practice”, Prentice Hall; $2^{\text {nd }}$ edition, 1992.

[13] A. Yablon, “Optical Fiber Fusion Splicing”, Springer; pp 6, 2005.

[14] M. Matthewson, C Kurkjian, "Environmental Effects on the Static Fatigue of Silica Optical Fiber," Journal of the American Ceramic Society, vol. 71, 1988, pp. 177-183.

[15] M. Matthewson, C Kurkjian, and R. Hamblin, "Acid stripping of fused silica optical fibers without strength degradation," Journal of lighwave technology, vol. 15, 1997, pp. 490-497.

[16]R.S. Robinson, H.H. Yuce, "Scanning Tunneling Microscopy of Optical Fiber Corrosion: Surface Roughness Contribution to Zero-Stress Aging," Journal of the American Ceramic Society, vol. 74, pp. 814-818, 1991.

[17] S. Bandyopadhyay, J. Canning, M. Stevenson, and K. Cook, "Ultra high temperature regenerated gratings in boroncodoped germanosilicate optical fiber using 193 nm," Optics Letters, vol. 33, no. 16, pp. 1917-1919, 2008.

[18]F. Anderegg, "Strength of Glass Fiber", Industrial and Eng Chemistry, vol 31, no 3, pp 290-298, 1939.

[19] J. Krause, S Kher, D. Stroumbakis, "Arc fusion splices with near pristine strengths and improved optical loss", $22^{\text {nd }}$ European Conf on Opt Comm, no. 2, pp237-240, 1996.

[20] M. Matthewson, C Kurkjian, C Haines, N. Venugopal, "Temperature dependence of strength and fatigue of fused silica fiber in the range 77 to 473K”, Proc SPIE, vol 4949, 2003. 